\title{
Genetic parameters of body weight, egg production and shell quality traits in the Brown Tsaiya laying duck
}

\author{
YS Cheng ${ }^{1,2}, \mathrm{R}_{\text {Rouvier }}{ }^{1}, \mathrm{JP}$ Poivey ${ }^{1}, \mathrm{C}$ Tai $^{2 *}$ \\ ${ }^{1}$ Institut national de la recherche agronomique, \\ station d'amélioration génétique des animaux, \\ centre de recherches de Toulouse, BP 27, F 31326 Castanet-Tolosan cedex, France; \\ ${ }^{2}$ Taiwan Livestock Research Institute, Hsin-Hua, Tainan, 71210 Taiwan, \\ Republic of China
}

(Received 13 June 1994; accepted 1st June 1995)

Summary - Heritabilities and genetic correlations were estimated for 5575 laying Brown Tsaiya ducks on performance data from 5 generations of a selection experiment, by means of a multivariate, multimodel, restricted maximum likelihood method (MM-REML) applied to an animal model on the 12 traits: feather length at 20 weeks of age (FL20); body weight at 20 and 40 weeks of age (BW20; BW40); age at first egg (AGE1EGG); number of eggs laid up to 40 and 52 weeks of age (NEGG40; NEGG52); eggshell strength at 30 and 40 weeks of age (ES30; ES40); egg weight at 30 and 40 weeks of age (EW30; EW40); egg yolk weight at 40 weeks of age (EYW40); and the proportion of egg weight to body weight at 40 weeks of age (EW40/BW40). Adult females were heavier than adult males (BW40: $1391 \mathrm{~g}$ vs $1310 \mathrm{~g})$. ES40 was lower than ES30 $\left(3.5 \mathrm{~kg} / \mathrm{cm}^{2}\right.$ vs $3.8 \mathrm{~kg} / \mathrm{cm}^{2}$. Heritabilities were found to be low $(0.094,0.107,0.118,0.160,0.169,0.191$ and 0.201 for ES40, ES30, NEGG52, NEGG40, FL20, EYW40 and AGE1EGG, respectively), to medium $(0.327,0.329,0.353,0.425$ and 0.499 for EW40/BW40, EW40, EW30, BW20 and BW40, respectively). Fifty genetic correlations were tabulated. The pattern of the genetic correlations for the traits to be selected showed that NEGG52 was highly positively correlated with NEGG40 ( $r g=0.948)$, uncorrelated with the body weight and was negatively correlated with AGE1EGG $(r g=-0.749)$, EW40 $(r g=-0.323)$, EW30 $(r g=-0.200), \operatorname{EYW} 40(r g=-0.340), \operatorname{ES} 30(r g=-0.194), \mathrm{ES} 40(r g=-0.203)$, FL20 $(r g=-0.131)$ and EW40/BW40 $(r g=-0.259)$. Egg weights, body weights and eggshell strength traits were positively genetically correlated among themselves. The results suggest that a linear selection index for NEGG52 with constraints for EW40, BW40 and ES40 could be an efficient tool for improving the efficiency of egg production with this small body type laying duck.

heritability / genetic correlation / animal model / laying duck

\footnotetext{
* Correspondence and reprints
} 
Résumé - Paramètres génétiques des caractères de poids corporels, de production d'œufs, et de qualité de la coquille chez la cane pondeuse Tsaiya Brune. Les héritabilités et corrélations génétiques ont été estimées pour 5575 pondeuses Tsaiya Brune, sur la base de performances concernant les 5 premières générations d'une expérience de sélection par la méthode du REML-MM (maximum de vraisemblance restreinte-multivariate multimodèle) appliquée à un modèle animal sur 12 caractères : la longueur de la plume à l'âge de $20 \mathrm{sem}$ (FL20), le poids corporel à 20 et $40 \mathrm{sem}$ (BW20; $B W 40$ ), l'âge au premier auf (AGE1EGG), les nombres d'œufs à 40 et 52 sem (NEGG40; NEGG52), la solidité de la coquille à 30 et 40 sem (ES30; ES40), le poids des æufs à 30 et $40 \mathrm{sem}$ (EW30; EW40), le poids des jaunes d'oufs à $40 \mathrm{sem}$ (EYW40) et le rapport $d u$ poids de l'œuf au poids corporel à $40 \mathrm{sem}(E W 40 / B W 40)$. Les femelles adultes étaient plus lourdes que les mâles ( $B W 40: 1391$ vs $1310 \mathrm{~g}$ ). ES40 était inférieure à ES30 (3,5 vs $3,8 \mathrm{~kg} / \mathrm{cm}^{2}$ ). Les valeurs d'héritabilité d'ES40, ES30, NEGG52, NEGG40, FL20, EYW40 et $A G E 1 E G G$ étaient faibles : 0,094;0,107;0,118;0,160;0,169;0,191 et 0,201 respectivement. Elles étaient de 0,$327 ; 0,329 ; 0,353 ; 0,425$ et 0,499 pour $E W 40 / B W 40, E W 40$, EW30, BW20 et BW40. Cinquante corrélations génétiques sont tabulées. NEGG52 était fortement corrélé avec $N E G G 40$ ( $\mathrm{rg}=0,948)$, mais n'était pas corrélé avec les poids corporels et était corrélé négativement avec AGE1EGG $(\mathrm{rg}=-0,749), E W 40(\mathrm{rg}=-0,323)$, $E W 30(\mathrm{rg}=-0,200), E Y W 40(\mathrm{rg}=-0,340), E S 30(\mathrm{rg}=-0,194), E S 40(\mathrm{rg}=-0,203)$, FL20 $(\mathrm{rg}=-0,131)$ et $E W 40 / B W 40(\mathrm{rg}=-0,259)$. Les poids des oufs, les poids corporels et les caractères de la solidité de la coquille étaient positivement corrélés entre eux. Les résultats suggèrent qu'une sélection sur un index linéaire pour NEGG52 avec des contraintes pour EW40, BW40 et ES40 pourrait être efficace pour améliorer les performances de la production d'ouf de la cane Tsaiya Brune.

héritabilité / corrélation génétique / modèle animal / cane pondeuse

\section{INTRODUCTION}

Twelve traits relating to feather length, body weights, egg production, egg weights and eggshell quality have been recorded in a selected Brown Tsaiya laying duck strain (L105) at the Duck Research Center, Ilan, Taiwan Livestock Research Institute since 1984 (Tai et al, 1994). Not much is known about the genetic parameters and especially the genetic correlations for these traits in ducks. Tai et al (1989) estimated heritabilities for 8 of these traits in the first generation. Lee et al (1992) estimated genetic parameters in each of the first 4 generations, using variance component estimation method applied to a hierarchical relationship structure. On the other hand, the best linear unbiased prediction (BLUP) (Henderson, 1988) has been increasingly applied to an animal model for predicting the genetic merit of candidates for selection in most species of farm animals. For this purpose estimates of the genetic parameters in the base population are required. Some simulation research has shown that the use of maximum likelihood (ML) or minimum variance quadratic unbiased estimation (MIVQUE) methods on selected data can lead to unbiased estimates of additive genetic variance in the base population (Rothschild et al, 1979; Meyer and Thompson, 1984; Sorensen and Kennedy, 1984). It has been shown that when the method of restricted maximum likelihood (REML, Patterson and Thompson, 1971) is applied to an animal model, in particular when 
all the information contributing to selection is included in the analysis and a large number of additive loci is assumed, it can provide unbiased estimation in selected populations (Kennedy, 1990; Meyer, 1990, 1991). Consequently, REML has recently been applied in animal breeding for estimating variance and covariance components in selected populations (Hofer et al, 1992; Besbes, 1993; Ducos et al, 1993; Hagger, 1994; Mielenz et al, 1994; Poujardieu et al, 1994). As far as we know, it has not yet been used to estimate genetic parameters in laying ducks.

The purpose of this study was to estimate and discuss genetic parameters for the 12 traits recorded for the first 5 generations in a selection experiment for laying Brown Tsaiya ducks.

\section{MATERIALS AND METHODS}

\section{Data description}

The ducks were collected from 4 different locations around Taiwan. Sires came from 4 breed farms and dams from another 4 egg-production farms. With 4 -by-4 mating, each origin of sire was mated to the 4 origins of dams ( 5 ducks per drake) and then progeny was assigned to mating groups depending on the sire origins. Twelve traits were individually measured and recorded as follows:

FL20: feather length at 20 weeks of age (except in 2nd and 4th generations) in both sexes.

BW20, BW40: body weight at 20 and 40 weeks of age respectively in both sexes. AGE1EGG: age at first egg.

NEGG40, NEGG52: number of eggs laid up to 40 and 52 weeks of age, respectively. ES30: eggshell strength at 30 weeks of age (except in 4th and 5th generations).

ES40: eggshell strength at 40 weeks of age (except in 1st and 2nd generations).

EW30, EW40: egg weight at 30 and 40 weeks of age, respectively.

EYW40: egg yolk weight at 40 weeks of age (except in first generation).

EW40/BW40: the ratio of egg weight to body weight at 40 weeks of age.

Eggs laid over 5 consecutive days at 30 and 40 weeks of age were weighed and measured by eggshell strength meters for the average of EW30, EW40, ES30 and ES40.

The structure of the selection experiment (without control strain) is described in table I for the number of ducks (males and females) and the hatching date of each generation. Population size was increased from the third generation mainly in order to maintain an optimal population size for long-term selection (Lee et al, 1992). A 2 -stage selection was carried out. First, $50 \%$ of the female ducks were selected on a linear phenotypic selection index:

$$
I=0.099 \cdot \mathrm{EW} 40(\mathrm{~g})-0.277 \cdot \mathrm{BW} 40(100 \mathrm{~g})+0.026 \cdot \mathrm{NEGG} 52(\mathrm{eggs})
$$

Among these selected females, the top 50\% were selected for ES30 (first and second generations) or ES40 (third to fifth generations). The drakes were similarly chosen taking into account the performances of their full and half sisters. 
Table I. Structure of the selection experiment.

\begin{tabular}{|c|c|c|c|c|c|}
\hline Generation & Origin $^{\mathrm{a}}$ & $\begin{array}{l}\text { Number } \\
\text { of hatch }\end{array}$ & Hatch period & Offspring & Parents ${ }^{\mathrm{b}}$ \\
\hline G0 & $\begin{array}{l}4 \text { origins of sire } \\
4 \text { origins of dam }\end{array}$ & - & - & - & $\begin{array}{l}M=40 \\
F=156\end{array}$ \\
\hline G1 & $\begin{array}{l}1051 \\
1052 \\
1053 \\
1054\end{array}$ & 5 & $24 / 12 / 84-21 / 01 / 85$ & $\begin{array}{r}M=111 \\
F=537\end{array}$ & $\begin{aligned} M & =18 \\
F & =121\end{aligned}$ \\
\hline G2 & $\begin{array}{ll}1 & 051 \\
1 & 052 \\
1 & 053 \\
1 & 054\end{array}$ & 4 & $08 / 12 / 86-30 / 12 / 86$ & $\begin{aligned} M & =161 \\
F & =450\end{aligned}$ & $\begin{aligned} M & =34 \\
F & =113\end{aligned}$ \\
\hline G3 & $\begin{array}{l}1051 \\
1052 \\
1053 \\
1054\end{array}$ & 5 & $21 / 03 / 88-19 / 04 / 88$ & $\begin{aligned} M & =40 \\
F & =449\end{aligned}$ & $\begin{aligned} M & =30 \\
F & =117\end{aligned}$ \\
\hline G4 & $\begin{array}{ll}1 & 051 \\
1 & 052 \\
1 & 053 \\
1 & 054\end{array}$ & 6 & $15 / 11 / 89-19 / 12 / 89$ & $\begin{aligned} M & =797 \\
F & =934\end{aligned}$ & $\begin{aligned} M & =30 \\
F & =108\end{aligned}$ \\
\hline G5 & $\begin{array}{l}1051 \\
1052 \\
1053 \\
1054\end{array}$ & 6 & $20 / 05 / 91-24 / 06 / 91$ & $\begin{aligned} M & =624 \\
F & =1112\end{aligned}$ & $\begin{aligned} M & =31 \\
F & =130\end{aligned}$ \\
\hline Total & & 26 & & $\begin{aligned} M & =2093 \\
F & =3482\end{aligned}$ & \\
\hline
\end{tabular}

a Four origins: $1051,1052,1053,1054 ;{ }^{b}$ parents of the next generation offspring: $M=$ number of males, $F=$ number of females.

\section{Statistical analysis}

All records were analysed by an SAS univariate procedure to test normal distribution, and some extreme and abnormal data were discarded (less than 3 depending on the trait). Skewed distributions were observed for the AGE1EGG, NEGG40 and NEGG52 variables. They were thus transformed using a power distribution (Box and Cox, 1964; Besbes et al, 1993) in order to satisfy the classical hypotheses for normally distributed traits. This transformation relies on a single parameter $t$ as shown previously for laying hens (Ibe and Hill, 1988; Besbes et al, 1992). The following formula was used:

$$
g_{t}(y)= \begin{cases}\frac{y^{t}-1}{t \ddot{y}^{(t-1)}} & \text { if } t \neq 0 \\ \log y & \text { if } t=0\end{cases}
$$


where $\ddot{y}$ is the geometric mean of the original observations. The parameter $t$ was empirically chosen is such a way that skewness became close to zero and there was a low residual sum of squares in the genetic model used to describe the data. The $t$ values were 3.8, 3.0 and -1.2, respectively, for NEGG52, NEGG40 and AGE1EGG.

Analysis of FL20, BW20 and BW40 was based on the following linear model:

$$
y_{i j k l}=\mu+H_{i}+S_{j}+a_{i j k}+e_{i j k l}
$$

where for AGE1EGG, NEGG40, NEGG52, ES30, ES40, EW30, EW40, EYW40 and EW40/BW40 the following model was used:

$$
y_{i k l}=\mu+H_{i}+a_{i k}+e_{i k l}
$$

where $y_{i j k l}$ and $y_{i k l}$ are the $i j k l$ th and $i k l$ th observations respectively, $\mu$ is the population mean, $H$ is the fixed effect for the $i$ th hatch, $S$ is the fixed effect for the $j$ th sex, $a_{i j k}$ and $a_{i k}$ are the random additive genetic effects of the $i j k$ th and $i k$ th animals respectively, and $e_{i j k l}$ and $e_{i k l}$ are the residual effects.

Sires from the 4 origins were considered to belong to the same population. The data for the 4 lines were pooled. Heritabilities and genetic correlations were estimated by the restricted maximum likelihood method (REML) applied to an animal model. A derivative-free REML algorithm (Graser et al, 1987) from the DFREML program of Groeneveld and Kovac (1990a,b) as adapted by Boichard (1994) and the VCE multivariate multimodel REML (co)variance component estimation (MM-REML) program of Groeneveld (1994a) were used for all trait analyses.

\section{Computing strategy}

The general linear model is as follows:

$$
\mathbf{y}=\mathbf{X} \boldsymbol{\beta}+\mathbf{Z u}+\mathbf{e}
$$

With $\mathrm{E}[\mathbf{y}]=\mathbf{X} \boldsymbol{\beta}, \mathrm{E}[\mathbf{u}]=0$ and $\mathrm{E}[\mathbf{e}]=0$

$$
\operatorname{Var}\left[\begin{array}{l}
\mathbf{y} \\
\mathbf{u} \\
\mathbf{e}
\end{array}\right]=\left[\begin{array}{ccc}
\mathbf{Z G} \mathbf{Z}^{\prime}+\mathbf{R}=\mathbf{V} & \mathbf{Z G} & \mathbf{R} \\
\mathbf{G} \mathbf{Z}^{\prime} & \mathbf{G} & \mathbf{0} \\
\mathbf{R} & \mathbf{0} & \mathbf{R}
\end{array}\right]
$$

where

$\mathbf{y}=$ vector of observations for the trait;

$\boldsymbol{\beta}=$ vector of fixed effects;

$\mathbf{u}=$ vector of animal effects;

$\mathbf{e}=$ random vector of residual effects;

$\mathbf{X}, \mathbf{Z}$ are incidence matrices relating observations to the effects in the model, $\mathbf{G}=\mathbf{A} \otimes \mathbf{G}_{0} ; \mathbf{A}$ is the numerator relationship matrix; $\mathbf{G}_{0}$ is the (co)variance matrix for additive genetic effects among traits; $\mathbf{R}=\mathbf{L}_{\mathrm{e}} \otimes \mathbf{R}_{\mathrm{o}} ; \mathbf{I}_{\mathbf{e}}$ is the identify matrix; $\mathbf{R}_{\mathrm{o}}$ is the residual (co)variance among traits; $\otimes=$ the Kronecker product.

The mixed-model equations (MME) are then (Henderson, 1963, 1973):

$$
\left[\begin{array}{cc}
\mathbf{X}^{\prime} \mathbf{R}^{-1} \mathbf{X} & \mathbf{X}^{\prime} \mathbf{R}^{-1} \mathbf{Z} \\
\mathbf{Z}^{\prime} \mathbf{R}^{-1} \mathbf{X} & \mathbf{Z}^{\prime} \mathbf{R}^{-1} \mathbf{Z}+\mathbf{G}^{-1}
\end{array}\right]\left[\begin{array}{l}
\widehat{\boldsymbol{\beta}} \\
\widehat{\mathbf{u}}
\end{array}\right]=\left[\begin{array}{c}
\mathbf{X}^{\prime} \mathbf{R}^{-1} \mathbf{y} \\
\mathbf{Z}^{\prime} \mathbf{R}^{-1} \mathbf{y}
\end{array}\right]
$$


The logarithm of the restricted, multivariate, normal likelihood function to be maximized is as follows (Groeneveld, 1994b):

$$
L V=\mathbf{y}^{\prime} \mathbf{R}^{-1} \mathbf{y}-\mathbf{y}^{\prime} \mathbf{R}^{-1} \mathbf{W b}^{\circ}+\log \left|\mathbf{C}^{*}\right|+n a \log \left|\mathbf{G}_{\circ}\right|+n \log \left|\mathbf{R}_{0}\right|
$$

where $L V$ is proportional to the logarithm of the likelihood function; $\mathbf{W}=(\mathbf{X} \mid \mathbf{Z})$; $\mathbf{b}^{\circ}$ is the solution vector of the $\mathrm{MME} ; \mathbf{C}^{*}$ is the inverse of the coefficient matrix of the MME; $n a=$ the number of animals; and $n=$ the number of observations. The log likelihood value was maximized by a Downhill-Simplex procedure or a QuasiNewton algorithm method and MME were solved by Cholesky factorization using a super-nodal block factorization (Groeneveld, 1994a,b).

The number of levels for fixed effects was 26 for hatch and 2 for sex. Heritabilities and genetic correlations were estimated with an animal model, taking all ducks which had at least one observation. The selected traits EW40, BW40, NEGG52, ES30 and ES40 were included together in the MM-REML analysis to obtain heritabilities and genetic correlations for the 5 traits selected. Each of the secondary traits was then added to study correlations between selected traits and 7 secondary traits. Finally the 7 secondary traits were analyzed together for genetic correlations. All relationship coefficients were calculated from the founder stock (G0) and all duck measurements from G1 to G5 were considered.

\section{Management}

The same management system described by Tai et al (1989) was applied throughout the 5 generations of selection in this study.

\section{RESULTS}

Tables II and III give the number of animals, and the means and standard deviations of phenotypic values for the 12 traits over 5 generations. Table IV gives the estimated heritability values (univariate model with DF-REML method) for 8 traits including untransformed and transformed variables. It also compares our values with those found by Tai et al (1989) and Lee et al (1992) for the first generation of the same population. Heritability values were only increased slightly following the Box-Cox transformation, especially for NEGG52 and NEGG40. So only the untransformed variables will be studied. Previous studies yielded heritabilities from the sire variance component $\left(h_{\mathrm{s}}^{2}\right)$ and the dam variance component $\left(h_{\mathrm{d}}^{2}\right)$. Our estimates are not very different from the $h_{\mathrm{s}}^{2}$ estimated values. Table $\mathrm{V}$ gives the estimates of heritability and genetic correlation values for the 5 selected traits achieved by MM-REML method analysis. Table VI gives heritabilities for the 7 secondary traits and their genetic correlations with the 5 selected traits. Table VII gives genetic correlations for 7 secondary traits. There was a group of low heritability values, $0.094,0.107,0.118,0.160,0.169,0.191$ and 0.201 for ES40, ES30, NEGG52, NEGG40, FL20, EYW40 and AGE1EGG, respectively, and a group of medium heritability values, 0.327, 0.329, 0.353, 0.425 and 0.499 for EW40/BW40, EW40, EW30, BW20 and BW40, respectively. FL20 was genetically positively correlated with AGE1EGG, body weight and egg weight traits, and 


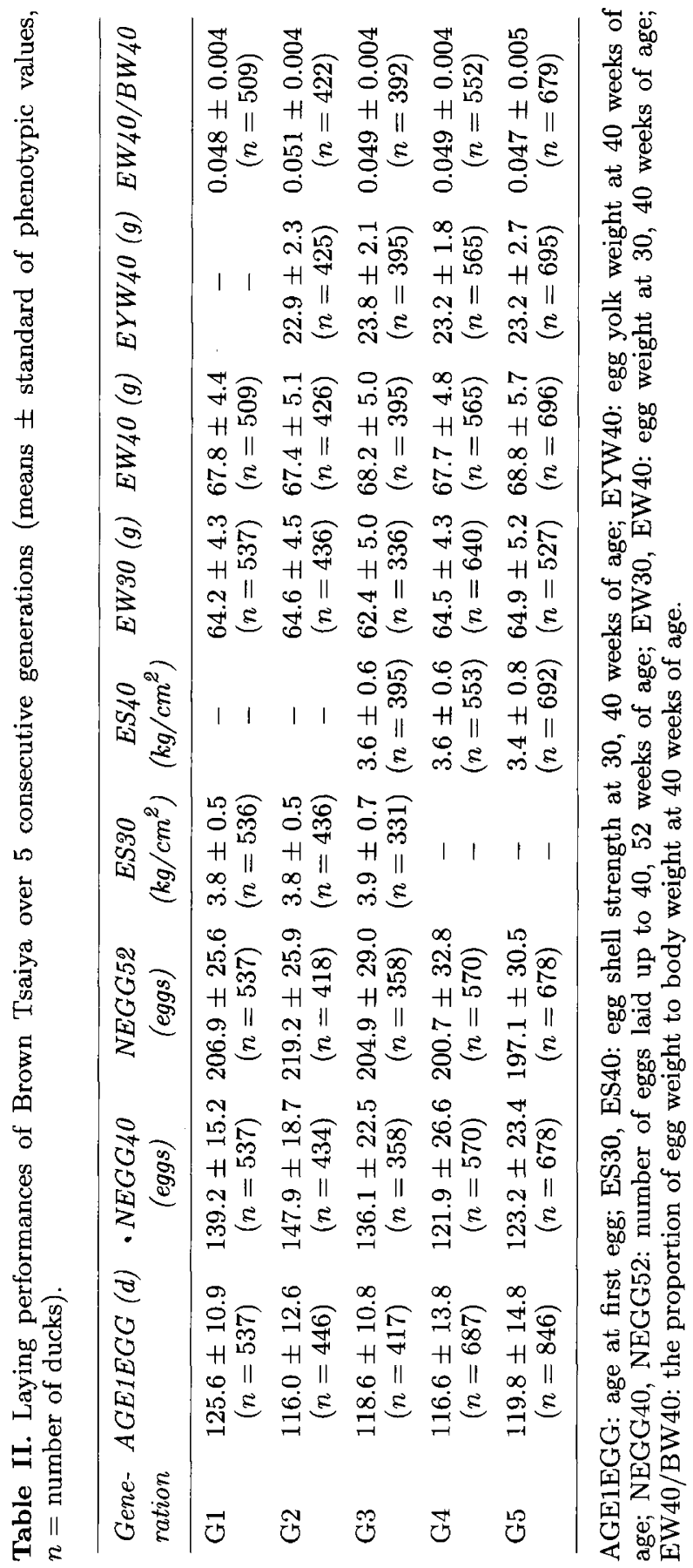


Table III. Growth performances of male and female Brown Tsaiya over 5 generations.

\begin{tabular}{|c|c|c|c|c|c|c|}
\hline \multirow{2}{*}{$\begin{array}{l}\text { Gene- } \\
\text { ration }\end{array}$} & \multicolumn{2}{|c|}{$F L 20(\mathrm{~cm})$} & \multicolumn{2}{|c|}{$B W 20(g)$} & \multicolumn{2}{|c|}{$B W 40(g)$} \\
\hline & Male & Female & Male & Female & Male & Female \\
\hline G1 & $\begin{array}{c}15.3 \pm 0.4 \\
(n=84)\end{array}$ & $\begin{array}{c}15.0 \pm 0.5 \\
(n=344)\end{array}$ & $\begin{array}{c}1263 \pm 108 \\
(n=111)\end{array}$ & $\begin{array}{c}1403 \pm 133 \\
(n=537)\end{array}$ & $\begin{array}{c}1343 \pm 111 \\
(n=111)\end{array}$ & $\begin{array}{c}1405 \pm 133 \\
(n=537)\end{array}$ \\
\hline G2 & - & $\begin{array}{l}- \\
-\end{array}$ & $\begin{array}{c}1248 \pm 103 \\
(n=161)\end{array}$ & $\begin{array}{c}1353 \pm 126 \\
(n=446)\end{array}$ & $\begin{array}{c}1272 \pm 136 \\
(n=149)\end{array}$ & $\begin{array}{c}1326 \pm 125 \\
(n=431)\end{array}$ \\
\hline G3 & $\begin{array}{c}15.6 \pm 0.6 \\
(n=116)\end{array}$ & $\begin{array}{c}15.5 \pm 0.7 \\
(n=224)\end{array}$ & $\begin{array}{c}1241 \pm 91 \\
(n=125)\end{array}$ & $\begin{array}{c}1317 \pm 117 \\
(n=401)\end{array}$ & $\begin{array}{c}1340 \pm 108 \\
(n=113)\end{array}$ & $\begin{array}{c}1379 \pm 118 \\
(n=402)\end{array}$ \\
\hline G4 & $\begin{array}{l}- \\
-\end{array}$ & $\begin{array}{l}- \\
-\end{array}$ & $\begin{array}{c}1329 \pm 111 \\
(n=223)\end{array}$ & $\begin{array}{c}1341 \pm 147 \\
(n=680)\end{array}$ & $\begin{array}{l}- \\
-\end{array}$ & $\begin{array}{c}1388 \pm 113 \\
(n=635)\end{array}$ \\
\hline G5 & $\begin{array}{c}15.3 \pm 0.6 \\
(n=350)\end{array}$ & $\begin{array}{c}15.1 \pm 0.6 \\
(n=636)\end{array}$ & $\begin{array}{c}1319 \pm 117 \\
(n=442)\end{array}$ & $\begin{array}{c}1418 \pm 150 \\
(n=827)\end{array}$ & $\begin{array}{c}1287 \pm 128 \\
(n=197)\end{array}$ & $\begin{array}{c}1459 \pm 152 \\
(n=769)\end{array}$ \\
\hline
\end{tabular}

FL20: feather length at 20 weeks of age; BW20, BW40: body weight at 20, 40 weeks of age.

slightly positively correlated with eggshell strength and EYW40, but slightly negatively correlated with egg production traits and EW40/BW40. Body weight traits were highly genetically correlated between themselves $(r g=0.988)$, and were positively correlated with egg weights, EYW40 and eggshell strength, but were not correlated with AGE1EGG and NEGG52. Age at first egg was negatively correlated with egg production traits, positively correlated with EYW40 and egg weight traits, and slightly positively correlated with ES40 and EW40/BW40. The 2 egg production traits were highly genetically correlated $(r g=0.948)$ between themselves and were negatively correlated with all other traits except BW40. ES30 and ES40 were highly correlated between themselves $(r g=0.845)$ and also EW30 and EW40 ( $r g=0.979)$. EYW40 was highly positively correlated with egg weight $(r g=0.870-0.914)$. Egg weight and EYW40 were positive correlated with eggshell strength $(r g=0.318-0.585)$. EW40/BW40 was highly negatively correlated with body weight $(r g=-0.686$ to -0.748$)$ and slightly negatively correlated with egg production traits and ES30, but was not correlated with EW40. It was positively correlated with EW30 and ES40. If computer facilities had not been limited, the MM-REML method could have been applied to take the whole selection process into account simultaneously and related genetic information could thus have been seen more clearly.

\section{DISCUSSION}

Unlike for poultry, very little data is available on the genetic parameters of laying duck traits. Pingel (1990) quotes 4 references for the heritability of egg number and egg weight in Pekin ducks. They vary from $h^{2}=0.23$ to 0.32 for egg number and from $h^{2}=0.23$ to 0.47 for egg weight. One value of $h^{2}=0.34$ has been found 


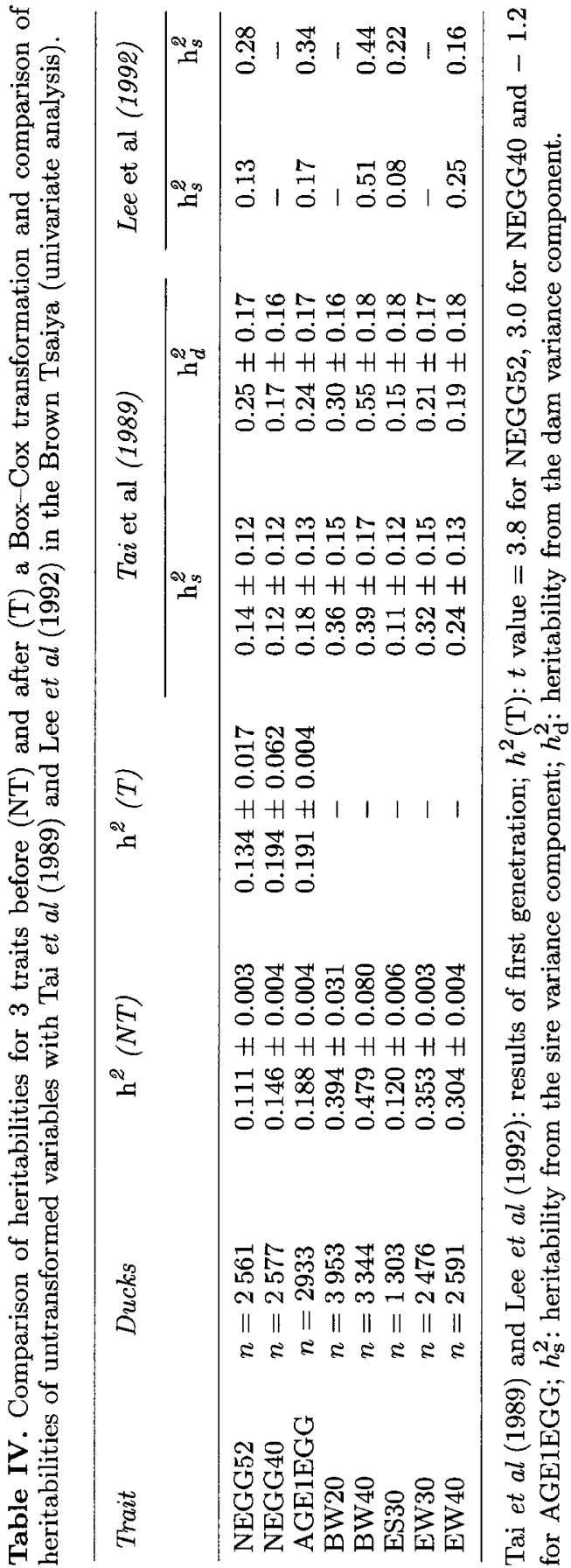


Table V. Heritabilities and genetic correlations $(r g)$ among 5 selected traits (5-variance analysis).

\begin{tabular}{lrrrrr}
\hline Trait & 1 & 2 & 3 & 4 & 5 \\
\hline EW40 & 0.329 & & & & \\
BW40 & 0.617 & 0.499 & & & \\
NEGG52 & -0.323 & 0.006 & 0.118 & & \\
ES30 & 0.583 & 0.472 & -0.194 & 0.107 & \\
ES40 & 0.483 & 0.231 & -0.203 & 0.845 & 0.094 \\
\hline
\end{tabular}

Heritabilities in the main diagonal; rg: below the diagonal.

Table VI. Heritabilites $\left(h^{2}\right)$ and genetic correlations $(r g)$ among 7 secondary traits and 5 selected traits (6-variate analysis for each secondary trait).

\begin{tabular}{lrrrrrr}
\hline & $E W 40$ & BW40 & NEGG52 & ES30 & ES40 & $\mathrm{h}^{2}$ \\
\hline FL20 & 0.488 & 0.428 & -0.131 & 0.055 & 0.115 & 0.169 \\
BW20 & 0.596 & 0.988 & -0.058 & 0.394 & 0.362 & 0.425 \\
AGE1EGG & 0.322 & 0.065 & -0.749 & -0.083 & 0.139 & 0.201 \\
NEGG40 & -0.354 & -0.090 & 0.948 & -0.106 & -0.333 & 0.160 \\
EW30 & 0.979 & 0.523 & -0.200 & 0.533 & 0.322 & 0.353 \\
EYW40 & 0.914 & 0.602 & -0.340 & 0.585 & 0.318 & 0.191 \\
EW40/BW40 & 0.054 & -0.748 & -0.259 & -0.130 & 0.121 & 0.327 \\
\hline
\end{tabular}

Table VII. Genetic correlations among 7 secondary traits (7-variate analysis).

\begin{tabular}{lrrcccc}
\hline & FL20 & BW20 & AGE1EGG & NEGG40 & EW30 & EYW40 \\
\hline BW20 & 0.460 & & & & & \\
AGE1EGG & 0.467 & 0.058 & & & & \\
NEGG40 & -0.167 & -0.148 & -0.757 & & & \\
EW30 & 0.392 & 0.463 & 0.220 & -0.214 & & \\
EYW40 & 0.184 & 0.532 & 0.338 & -0.385 & 0.870 & \\
EW40/BW40 & -0.109 & -0.686 & 0.187 & -0.135 & 0.303 & 0.088 \\
\hline
\end{tabular}

for the age at first egg. Richard et al (1983) found $h^{2}=0.16$ and 0.49 for egg number and age at first egg in Muscovy ducks. The conventional hierarchical analysis of variance was used to estimate the sire and dam within-sire variance components. Poujardieu et al (1994) presented genetic parameters in common duck for growth and cramming traits of male ducks estimated by an REML animal model. Some REML estimates in laying hens based on an additive animal model were reported recently. Besbes et al (1992) gave estimates of heritabilities for egg production traits (numbers of eggs between 19 to 26,26 to 38 and 26 to 54 weeks of age) which were $0.25,0.09$ and 0.18 , respectively. Their heritabilities for egg weight and body weight were 0.47 and 0.50 , respectively. Wei and van der Werf (1993) estimated additive and dominance variances in White Leghorn lines and reported high heritability 
values for egg numbers. Hagger (1994) found $h^{2}=0.292$ for NEGG40, $h^{2}=0.754$ for EW40, and $h^{2}=0.790$ and 0.732 for male and female BW40. Mielenz et al (1994) reported $h^{2}=0.40$ for egg number up to day $270, h^{2}=0.75$ and 0.62 for egg weight and body weight at day 215 . These reports have generally shown higher heritabilities than those of Brown Tsaiya especially for egg number. In poultry, the values from Besbes et al (1992) were the closest to our results for Brown Tsaiya.

A sex effect was introduced in the model of analysis for body weight and feather length, because males Brown Tsaiya are significantly lighter than females. This is quite unusual if we compare them with Muscovy ducks where there is a very large sexual dimorphism for body weight in favor of males, but also with Pekin ducks, in which the males are $10 \%$ heavier than the females.

Taking all the information from the selected traits enables the best use of MMREML in an animal model in order to get unbiased estimates of the genetic parameters in the base population. Owing to limited computing facilities, we calculated the genetic parameters for the 5 selected traits included together in the MM-REML analysis. It was assumed that the genetic parameters should be consistent at least for these traits and also the genetic correlations of these 5 selected traits along with the 7 secondary trait ones. The heritability values calculated by univariate or multivariate REML are very close and the maximum difference is only $3 \%$.

The estimates of the heritabilities of the 12 traits and their genetic correlations could provide a basic knowledge of the genetic parameters in the base population of this laying Brown Tsaiya line selected for 5 generations. The main purpose of breeding could be to increase additive genetic value for egg production traits while getting a moderate body weight and keeping egg weight and eggshell quality at optimum levels according to market requirements. ES40 is lower on average than ES30. So it seems better to take ES40 as a selection criterion for eggshell strength. Heritability values of egg production traits in Brown Tsaiya are small but there is some additive genetic variation, and selection for NEGG52 is possible. The same is true for eggshell quality traits. NEGG40 and NEGG52 are slightly negatively correlated with ES30 and negatively correlated with ES40. They are negatively correlated with EW40 and EYW40, and slightly negatively correlated with EW30. EW40 is highly correlated with EYW40 and behaves as if it were the same trait. BW20 and BW40 behave genetically as the same trait, with BW20 being slightly negatively correlated with egg production up to 52 weeks of age, but BW40 showing no genetic correlation with egg number. Thus selection for egg number up to 40 or 52 weeks of age alone should be antagonistic to genetic progress in EW40 and ES40. Constraints for these 2 traits could be introduced into a selection index, the aim of which should be to increase egg number while maintaining EW40, BW40 and ES40 at their current levels.

In fact EW40/BW40 was found to be strongly influenced by body weights, with highly negative genetic correlations. When compared with laying hens, the Brown Tsaiya showed a good ratio of egg weight to body weight at 40 weeks of age (0.0489 vs 0.0316 (Liljedahl et al, 1979)). The Brown Tsaiya ducks already have quite a moderate body weight. In order to improve egg production, egg weight/body weight ratio and feed efficiency by limiting maintenance cost, it seems that ducks of small body type should be considered. Besbes et al (1992) also showed a genetic 
correlation of -0.14 (line A) or -0.22 (line B) between egg number and egg weight, 0.32 (line A) or 0.33 (line B) between egg weight and body weight and 0.25 (line A) or -0.12 (line B) between egg number and body weight. The results indicated that different lines could exhibit different genetic correlations between egg number and body weight. Hagger (1994) estimated that genetic correlations between NEGG40 and EW40 was -0.267 and that between NEGG40 and male and female BW40 were -0.161 and -0.036 , respectively, with the genetic correlations between EW40, male and female BW40 being 0.338 and 0.294, respectively. Mielenz et al (1994) reported genetic correlations among egg number up to day 270 , egg weight and body weight at day 215 were -0.11 and 0.07 , respectively, and 0.39 between egg weight and body weight at day 215 . Obviously, the genetic correlations between egg number and body weight can vary according to line and sex as found in laying hens, whereas Brown Tsaiya showed no genetic correlations between them. It could be concluded that in laying hens most of the heritabilities estimated by the REML animal model showed higher values for egg number than in Brown Tsaiya, and the genetic correlations reported among traits were also different.

Once the heritabilities and genetic correlations in the base popultion are known, the breeder can define a selection strategy by selecting for a linear combination of the predicted breeding values of the 4 traits EW40, BW40, NEGG52 and ES40. The optimal linear combination can be chosen according to the expected correlated responses for the several traits.

\section{ACKNOWLEDGMENTS}

This study was undertaken as a cooperative research project between the Council of Agriculture-Taiwan Livestock Research Institute (Taiwan Provincial Department of Agriculture and Forestry) (COA-TLRI) and the Institut national de la recherche agronomique, station d'amélioration génétique des animaux (INRA-SAGA). We should like to thank all of the staff at TLRI (especially Ilan Sub-Institute of TLRI) and SAGA for their help in carrying out this research and also INRA-SAGA and COA-TLRI for their financial support.

\section{REFERENCES}

Besbes B (1993) Évaluation de souches de poules pondeuses à l'aide de la méthodologie du BLUP. Thèse de doctorat en sciences, INA, Paris-Grignon, France

Besbes B, Ducrocq V, Foulley JL, Protais M, Tavernier A, Tixier Boichard M, Beaumont C (1992) Estimation of genetic parameters of egg production traits of laying hens by restricted maximum likelihood applied to a multiple-trait reduced animal model. Genet Sel Evol 24, 539-552

Besbes B, Ducrocq V, Foulley JL, Protais M, Tavernier A, Tixier Boichard M, Beaumont C (1993) Box-Cox transformation of egg production traits of laying hens to improve genetic parameter estimation and breeding evaluation. Livest Prod Sci 33, 313-326

Boichard D (1994) Programme DF-REML description et notice d'utilisation. INRA, SGQA, Jouy-en-Josas, France

Box GPE, Cox DR (1964) An analysis of transformations. $J R$ Stat Soc B26, 211-243

Ducos A, Bidanel JP, Ducrocq V, Boichard D, Groeneveld E (1993) Multivariate restricted maximum likelihood estimation of genetic parameters for growth, carcass and meat 
quality traits in French Large White and French Landrace pigs. Genet Sel Evol 25, 475-493

Graser HU, Smith SP, Tier B (1987) A derivative-free approach for estimating variance components in animal models by restricted maximum likelihood. J Anim Sci $64,1362-$ 1370

Groeneveld E (1994a) VCE-a multivariate multimodel REML (co)variance component estimation packages. In: Proc 5th World Congress Genetics Applied to Livestock Production, University of Guelph, Guelph, ON, Canada 22, 47-48

Groeneveld E (1994b) A reparameterization to improve numerical optimization in multivariate REML (co)variance component estimation. Genet Sel Evol 26, 537-545

Groeneveld E, Kovac M (1990a) A generalized computing procedure for setting up and solving mixed linear models. J Dairy Sci 73, 513-531

Groeneveld E, Kovac M (1990b) A note on multiple solution in multivariate restricted maximum likelihood covariance component estimation. J Dairy Sci 73, 2221-2229

Hagger C (1994) Genetic correlations between body weight of cocks and production traits in laying hens, and their possible use in breeding schemes. Poult Sci 73, 381-387

Henderson CR (1963) Selection index and expected genetic advance. In: Statistical Genetics and Plant Breeding (WD Hanson, HF Robinson, eds), National Academy of Sciences-National Research Council, Washington, DC, publication 982, 141-163

Henderson CR (1973) Sire evaluation and genetic trend. In: Proc Animal Breeding and Genetics Symposium in honor of DR JL Lush, Am Soc Anim Sci and Am Dairy Sci Assoc, Champaign, IL, 10-41

Henderson CR (1988) Theoretical basis and computational methods for a number of different animal models. J Dairy Sci 71 (suppl 2) 1-16

Hofer A, Hagger C, Künzi N (1992) Genetic evaluation of on-farm tested pigs using an animal model. I. Estimation of variance components with restricted maximum likelihood. Livest Prod Sci 30, 69-82

Ibe SN, Hill WG (1988) Transformation of poultry egg production data to improve normality, homoskedasticity and linearity of genotypic regression. J Anim Breed Genet $105,231-240$

Kennedy BW (1990) Use of mixed model methodology in analysis of designed experiments. In: Advance in Statistical Methods for Genetic Improvement of Livestock (D Gianola, K Hammond, eds), Springer-Verlag, Berlin, 77-97

Lee SR, Huang JF, Sheu NS, Chen SY, Chen BJ, Jiang YN, Tai LJJ, Tai C (1992) Study on the performance of Brown Tsaiya duck (Anas Platyrhynchos var Domestica). Taiwan Livest Res 25, 35-48

Liljedahl LE, Kolstad N, Sørensen P, Maijala K (1979) Scandinavian selection and crossbreeding experiment with laying hens. I. Background and general outline. Acta Agric Scand 29, 273-286

Meyer K (1990) Present status of knowledge about statistical procedures and algorithms to estimate variance and covariance components. In: Proc 4th World Congress on Genetics Applied to Livestock Production, Edinburgh, Vol XIII, 407-418

Meyer K (1991) Estimating variance and covariances for multivariate animal models by restricted maximum likelihood. Genet Sel Evol 23, 67-83

Meyer K, Thompson R (1984) Bias in variance and covariance component estimators due to selection on a correlated trait. Z Tierz Züchtgsbiol 101, 33-50

Mielenz N, Groeneveld E, Müller J, Spilke J (1994) Simultaneous estimation of variance and covariances using REML and Henderson 3 in a selected population of White Leghorns. Br Poult Sci 35, 669-676

Patterson HD, Thompson R (1971) Recovery of inter-block information when block sizes are unequal. Biometrika 58, 545-554 
Pingel H (1990) Genetics of egg production and reproduction in waterfowl. In: Poultry Breeding and Genetics (RD Crawford, ed), Elsevier, Amsterdam, 771-780

Poujardieu B, Guichard F, Laventure P (1994) Paramètres génétiques de croissance et de gavage de la cane commune. Génét Sél Evol 26, 463-472

Ricard FH, Leclercq B, de Carville H (1983) Mise au point sur les caractéristiques génétiques et les méthodes d'élevage du canard de Barbarie. Ann Zootech 32, 189-200

Rothschild MF, Henderson CR, Quaas RL (1979) Effects of selection on variances and covariances of simulated first and second lactations. J Dairy Sci 62, 996-1002

Sorensen DA, Kennedy BW (1984) Estimation of genetic variances from unselected and selected populations. J Anim Sci 59, 1213-1223

Tai C, Rouvier R, Poivey JP (1989) Genetic parameters of some growth and egg production traits in laying Brown Tsaiya (Anas Platyrhynchos). Genet Sel Evol 21, 377-384

Tai C, Huang YJ, Tai LJJ, Chyr SC (1994) The construction of constraint selection indices in laying ducks. $J$ Chin Soc Anim Sci 23, 355-360

Wei M, van der Werf JHJ (1993) Animal model estimation of additive and dominance variances in egg production traits of poultry. $J$ Anim Sci 71, 57-65 